\title{
STUDI ANALISA DAMPAK LALU LINTAS DIKAWASAN PEMBANGUNAN GEDUNG OLAH RAGA KABUPATEN TRENGGALEK
}

\author{
Ela Mahudi *1, Yosef Cahyo S.P. ${ }^{2}$, Ahmad Ridwan ${ }^{3}$. \\ ${ }^{1,2,3}$ Fakultas Teknik, Universitas Kadiri. \\ e-mail:*1elamahudi27@yahoo.com, 22yosef.cs@unik-kediri.ac.id, \\ 33ahmadridwan@unik-kediri.ac.id.
}

\begin{abstract}
The construction of the Sports Building will lead to an increase in traffic volume. The study aims to find out the Average Daily Traffic, predicting the degree of saturation in the sections and intersections around the construction at peak hours in 2024 or after 5 years of the study is carried out. They are using data collection methods and transportation modeling methods as well as micro approaches for the analysis of transportation system performance. The results of the Average Daily Traffic Survey (LHR) are 0.50 with a service level of $C$. In the prediction in 2024, if there is no development in the area, the degree of saturation will be 0.70 with service level C. In 2024, if there is an increase in traffic flow. This happens because, based on the analysis, it is obtained generation of 71 pcs / hour and a pull of 129 pcs / hour. Average Daily Traffic (LHR) and Performance of roads and intersections around the Sports Hall in 2024 are still normal based on the degree of saturation of 0.70 and the level of service $C$. Suggestions and recommendations need to regulate vehicle circulation and installation of warning lights around the Sports Building.
\end{abstract}

Keywords: $\quad$ Movement, Degree Of Saturation, Prediction In 2024, The Performance Of Roads

\begin{abstract}
Abstrak
Pembangunan Gedung Olahraga akan menyebabkan peningkatan volume lalu lintas. Penelitian bertujuan untuk mengetahui Rata-rata Lalu Lintas Harian, memprediksi derajat kejenuhan pada ruas-ruas dan persimpangan di sekitar konstruksi pada jam puncak tahun 2024 atau setelah 5 tahun penelitian dilakukan. Mereka menggunakan metode pengumpulan data dan metode pemodelan transportasi serta pendekatan mikro untuk analisis kinerja sistem transportasi. Hasil Average Daily Traffic Survey (LHR) adalah 0,50 dengan service level C.Pada prediksi tahun 2024 jika tidak ada pembangunan di wilayah tersebut maka derajat kejenuhannya akan menjadi 0,70 dengan service level C. Pada tahun 2024, jika terjadi peningkatan arus lalu lintas. Hal ini terjadi karena berdasarkan analisis diperoleh pembangkitan $71 \mathrm{pcs} /$ jam dan tarikan 129 pcs / jam. Rata-rata Lalu Lintas Harian (LHR) dan Kinerja Jalan dan Persimpangan di sekitar Gedung Olah Raga pada tahun 2024 masih normal berdasarkan derajat kejenuhan 0,70 dan tingkat pelayanan C. Saran dan rekomendasi perlu pengaturan sirkulasi kendaraan dan pemasangan lampu peringatan di sekitar Gedung Olahraga.
\end{abstract}

Kata Kunci : $\quad$ Pergerakan, Derajat Kejenuhan, Prediksi Tahun 2024, Kinerja Ruas Jalan 


\section{PENDAHULUAN}

Jalan merupakan prasarana yang menghubungkan wilayah satu dengan wilayah lainnya. Denganadanya jalan kita bisa melakukan aktivitas sehari-hari dengan mudah [1][2].Parkir diluar ruang milik jalan baik pada mall-mall yang biasanya lahan parkir bertingkat atau pada perkantoran (biasanya kantor Pemerintahan) yang mempunyai lahan parkir horizontal yang luas, seringkali menimbulkan persoalan dalam masalah pencarian atau pelacakan tempat (lot) parkir yang masih kosong dimana kendaraan (mobil) akan berputar-putar atau naik-turun untuk mencari lot parkir yang masih kosong tersebut [3][4][5]. Dalam mengatasi persoalan diatas pengelola parkir atau manajemen parkir biasanya membantu pengguna parkir dengan memberikan info jumlah lot parkir yang kosong pada jalur yang dilalui pengguna parkir [6][7].

Namun, pertumbuhan penduduk yang besar menimbulkan banyak permasalahan. Salah satu permasalahan yang sering terjadi di kota- kota besar adalah permasalahan lalu lintas [8][9][10]. Masyarakat lebih memilih menggunakan kendaraan pribadi dibandingkan menggunakan kendaraan umum [11][12]. Hal ini dikarenakan kendaran pribadi dinilai lebih efisien daripada kendaraan umum. Dan akibatnya pun pertumbuhan kendaraan bermotor semakin tak terbendung.Salah satu contoh adalah kota Trenggalek. Salah satu titik yang ramai di Trenggalek terdapat di Jalan Brigjend Sutran. Dengan panjang jalan $6500 \mathrm{~m}$ dan lebar yang bervariasi dari $6 \mathrm{~m}-9 \mathrm{~m}$, menyebabkan kendaraan bertumpuk dibeberapa tempat [13][14]. Apalagi Jalan Brigjend Sutran termasuk jalan perkotaan,dengan status jalan kolektor sekunder,terdiri dari 2 arah 2 jalur,dan dilewati oleh berbagai kendaran seperti truk besar,bus,mobil,motor dan sepeda [15][16]. Disamping itu, pembangunan Gedung Olah Raga dan banyaknya persimpangan tak bersinyal semakin menambah masalah kepadatan arus pada ruas jalan Brigjend [13][17][18].

\section{METODE PENELITIAN}

\subsection{Lokasi Penelitian.}

Penelitian ini dilakukan di Laboratorium Teknik Sipil Universitas Kadiri, pada awal bulan maret dan selesai pada bulan juni dengan menggunakan metode Eksperimen.

\subsection{Pengumpulan dan Pengolahan Data}

Analisa ini digunakan untuk memprediksi jumlah kendaraan di tahun yang akan datang karena diperkirakan kendaraan tiap tahunnya semakin bertambah. Pada tugas akhir ini data yang diperoleh merupakan data selama 5 tahun, yaitu sejak tahun 2015 - 2019. Data yang digunakan terdiri dari data primer dan data sekunder. Pengumpulan data ini diperoleh dari hasil survey 
lapangan secara langsung dan dari instansi yang terkait. Data-data yang dimaksudkan sebagai berikut:

1. Data Primer

Data primer adalah data yang kita peroleh dengan cara terjun langsung dalam pencarian data. dikelompokkan menjadi data geometrik lalu lintas, volume lalu lintas, dan data kondisi lapangan/tata guna lahan. Di dalam geometrik lalu lintas terdapat data geometrik ruas jalan dan simpang [19]. Data volume lalu lintas berisi data survey/traffic counting kendaraan bermotor pada jam puncak. Sedangkan data kondisi lapangan/tata guna lahan adalah data yang mengelompokkan tata guna lahan.

\section{Data Sekunder}

Data sekunder data yang didapat dari sebuah instansi., tanpa kita terjun langsung dalam prosespencarian data. Data sekunder meliputi data peta lokasi, data jumlah penduduk, dan data jumlah pertumbuhan kendaraan bermotor.

\subsection{Pelaksanaan Survey.}

Pelaksanaan survey dilakukan dengan beberapa tahapan, diantaranya:

a. Persiapan Survey

Pelaksanaan survey lapangan diawali dengan persiapan yang meliputi penyiapan alat alat survey, pelatihan tenaga surveyor, penetapan lokasi definitif titik-titik survey, dan alokasi waktu.

\section{b. Survey Volume Kendaraan}

Survey volume kendaraan dilakukan dengan survey traffic counting pada ruas jalan dansimpang. Survey traffic counting dilakukan untuk mengetahui volume kendaraan yang melintas di sepanjang ruas jalan dan simpang di jalan Menur Pumpungan. Survey ini dilakukan dengan memilih hari efektif, yaitu 1 hari kerja (Selasa-Kamis). Pada pelaksanaan survey volume kendaraan, langkah pertama yang dilakukan dalam survey ini adalah menentukan titik survey. Survey volume lalu lintas ini dilakukan pada jam puncak pagi (06.0009.00), jam puncak siang (11.00-14.00), dan jam puncak sore (16.00-19.00).

\subsection{Analisa Prediksi Jumlah Kendaraan}

Analisa ini dilakukan untuk memprediksikan jumlah kendaraan di tahun yang akan datang karena diperkirakan kendaraan setiap tahunnya bertambah. Dan dalam menentukan pertumbuhan kendaraan di ruas jalan dapat menggunakan rumus suku berbunga dengan memakai data jumlah kendaraan pada tahun terakhir. Sedangkan pada penelitian ini data yang didapat adalah selama 5 tahunterakhir yaitu 2015-2019.

\subsubsection{Faktor Pertumbuhan Lalu Lintas}


Pertumbuhan lalu lintas pada tahun rencana tergantung jenis pada pertumbuhan masingmasing jenis kendaraan, dimana faktor pertumbuhan lalu lintas untuk masing-masing kendaraan tidaklah sama.

\subsubsection{Bangkitan Perjalanan}

Sistem pemodelan yang biasa dipakai adalah model analisis regresi linier [20],yang dapat ditulis sebagai berikut :

$f(x)=y=a+b(x)$

Dimana, :

a merupakan konstanta regresi.

b merupakan koefisien regresi.

\subsection{Tingkat Pelayanan atau Level of Service (LOS)}

Level Of Service (LOS) merupakan ukuran kualitas sebagai rangkaian dari beberapa factor yang mencakup kecepatan kendaraan dan waktu perjalanan, interupsi lalu-lintas, kebebasan untuk maneuver, keamanan, kenyamanan mengemudi, dan ongkos operasi (operation cost), sehingga LOS sebagai tolok ukur kualitas suatu kondisi lalu lintas, maka volume pelayanan harus kurang dari kapasitas jalan itu sendiri. LOS yang tinggi didapatkan apabila cycle time -nya pendek, sebab cycle time yang pendek akan menghasilkan delay yang kecil. Dalam klasifikasi pelayanan LOS dibagi menjadi 6 seperti pada tabel berikut ini:

Tabel 1. Tabel Tingkat Pelayanan (LOS)

\begin{tabular}{|c|c|c|}
\hline $\begin{array}{c}\text { Tingkat } \\
\text { Pelayanan }\end{array}$ & Rasio ( V/C ) & Karakteristik \\
\hline $\mathbf{A}$ & $<0,60$ & $\begin{array}{l}\text { Arus bebas, volume rendah dan kecepatan tinggi, } \\
\text { pengemudi dapat memilih kecepatan yang } \\
\text { dikehendaki }\end{array}$ \\
\hline $\mathbf{B}$ & $\begin{array}{l}0,60< \\
\mathrm{V} / \mathrm{C} \\
0,70\end{array}$ & $\begin{array}{l}\text { Arus stabil, kecepatan sedikit terbatas oleh lalu lintas, } \\
\text { pengemudimasih dapat bebas dalam memilih } \\
\text { kecepatannya. }\end{array}$ \\
\hline C & $\begin{array}{c}0,70 \\
<\mathrm{V} / \mathrm{C}<0,80\end{array}$ & Arus stabil, kecepatan dapat dikontrol oleh lalu lintas \\
\hline $\mathbf{D}$ & $\begin{aligned} & \mathrm{D} \quad 0,80< \\
& \mathrm{V} / \mathrm{C}<0,90\end{aligned}$ & $\begin{array}{l}\text { Arus mulai tidak stabil, kecepatan rendah dan } \\
\text { berbeda-beda, volumemendekati kapasitas }\end{array}$ \\
\hline $\mathbf{E}$ & $0,90<\mathrm{V} / \mathrm{C}<1$ & $\begin{array}{l}\text { Arus tidak stabil, kecepatan rendah dan berbeda- } \\
\text { beda, volumemendekati kapasitas }\end{array}$ \\
\hline
\end{tabular}




\begin{tabular}{|c|l|l|}
\hline $\mathbf{F}$ & $>1$ & $\begin{array}{l}\text { Arus yang terhambat, kecepatan rendah, volume } \\
\text { diatas kapasitas,sering terjadi kemacetan pada waktu } \\
\text { yang cukup lama }\end{array}$ \\
\hline
\end{tabular}

Sumber : MKJI 1997

\section{HASIL DAN PEMBAHASAN}

Dalam sistem transportasi tujuan dari perencanaan adalah penyediaan fasilitas untuk pergerakan penumpang atau barang dari satu tempat ke tempat lain atau dari berbagai pemanfaatan lahan.

\subsection{Prediksi Asal Tujuan Perjalanan Tanpa Pengembangan Tahun 2024}

Pembagian zona untuk kondisi saat ini meliputi :

- Zona 1 adalah pergerakan Jl. Panglima Sudirman dan Jl. Brigjend Sutran

- Zona 2 adalah pergerakan J1. Panglima Sudirman dan J1. Brigjend Sutran

- Zona 3 adalah pergerakan. Jl.Kanjeng Jimat, Jl. Khairil Anwar ,Jl. Brigjend Sutran

- Zona 4 adalah pergerakan Jl. Kanjeng Jimat,dan Jl. Brigjend Soetran

- Zona 5 adalah pergerakan Jl. Kanjeng Jimat,Jl. Ronggo warsito dan. Brigjend Sutran

- Zona 6 adalah pergerakan Jl. Kairil Anwar, Kanjeng Jimat dan Jl. Brigjend Sutran.

Tabel 2. Prediksi Asal Tujuan Perjalanan Pada Periode Puncak Pagi Tanpa

Pengembangan Tahun 2024

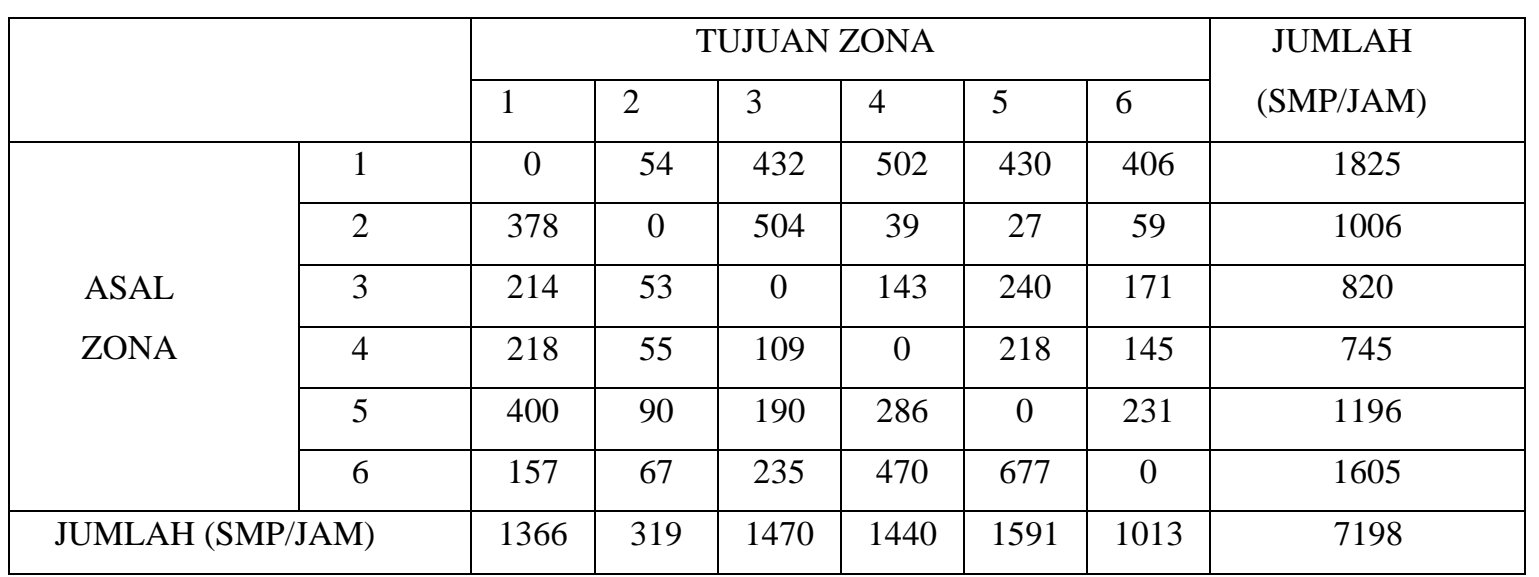

Sumber : Hasil Analisa

Tabel 3..Prediksi Asal Tujuan Perjalanan Pada Periode Puncak Siang Tanpa Pengembangan Tahun 2024

\begin{tabular}{|c|c|c|c|l|l|l|l|c|}
\hline \multicolumn{2}{|c|}{} & \multicolumn{6}{|c|}{ TUJUAN ZONA } & JUMLAH \\
\cline { 3 - 8 } & 1 & 2 & 3 & 4 & 5 & 6 & $($ SMP/JAM) \\
\hline & 1 & 0 & 56 & 452 & 440 & 354 & 313 & 1616 \\
\hline
\end{tabular}




\begin{tabular}{|l|c|c|c|c|c|c|c|c|}
\hline \multirow{2}{*}{$\begin{array}{l}\text { ASAL } \\
\text { ZONA }\end{array}$} & 2 & 360 & 0 & 480 & 240 & 80 & 35 & 1194 \\
\cline { 2 - 8 } & 3 & 191 & 53 & 0 & 127 & 143 & 160 & 674 \\
\cline { 2 - 8 } & 4 & 174 & 55 & 116 & 0 & 155 & 232 & 732 \\
\cline { 2 - 8 } & 5 & 428 & 32 & 129 & 286 & 0 & 255 & 1130 \\
\cline { 2 - 8 } & 6 & 281 & 36 & 231 & 462 & 477 & 0 & 1488 \\
\hline \multicolumn{2}{|l}{ JUMLAH (SMP/JAM) } & 1434 & 233 & 1407 & 1555 & 1210 & 995 & 6833 \\
\hline
\end{tabular}

Sumber : Hasil Analisa

Tabel 4. Prediksi Asal Tujuan Perjalanan Pada Periode Puncak Sore Tanpa

Pengembangan Tahun 2024

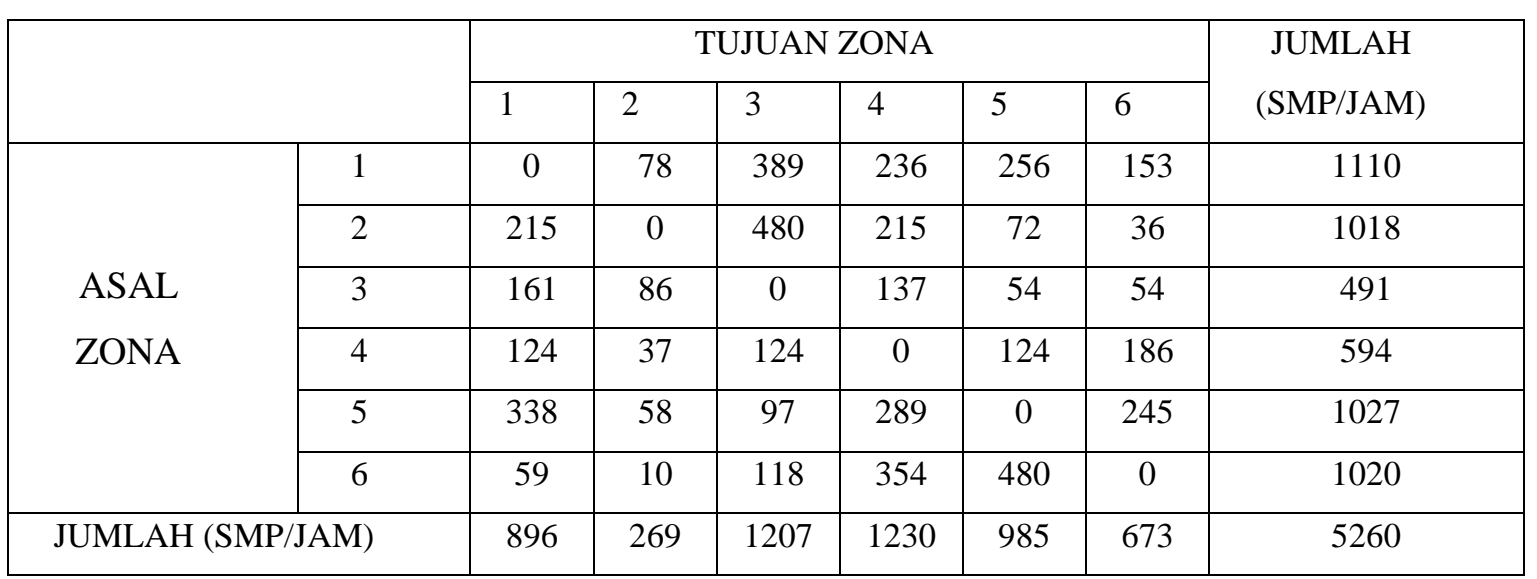

Sumber : Hasil Analisa

\subsection{Prediksi Kinerja Lalu-Lintas Tanpa Pengembangan Tahun 2024}

Untuk mengetahui kinerja jaringan jalan pada periode 5 tahun yang akan datang tanpa pengembangan, yaitu dengan melihat derajat kejenuhan atau yang biasa disebut V/C Rasio dan tingkat pelayanan (Level Of Service) lalu lintas pada masing-masing ruas jalan dan persimpangan yang ditinjau. Hasil analisa sebagaimana informasi berikut :

Tabel 5. Prediksi Volume, Kapasitas, Derajat Kejenuhan dan Tingkat Pelayanan Pada

Ruas Jalan Sekitar Lokasi Studi Tanpa Pengembangan Tahun 2024 Puncak Pagi

\begin{tabular}{|c|l|l|l|l|l|l|l|}
\hline No & Ruas & Type & $\begin{array}{l}\text { Perger } \\
\text { akan }\end{array}$ & $\begin{array}{l}\text { Volume } \\
(\text { smp/jam })\end{array}$ & $\begin{array}{l}\text { Kapasitas } \\
\text { (smp/jam })\end{array}$ & DS & LOS \\
\hline \multicolumn{7}{|c|}{ Puncak Pagi (06:00 s/d 09:00) } \\
\hline \multirow{2}{*}{1} & $\begin{array}{c}\text { Jl. Brigjend } \\
\text { Sutran }\end{array}$ & \multirow{2}{*}{$2 / 2 \mathrm{D}$} & $\mathrm{S}-\mathrm{U}$ & 1449 & 1692 & 0.86 & $\mathrm{E}$ \\
\cline { 4 - 9 } & Jl. Panglima & \multirow{2}{*}{$4 / 2 \mathrm{UD}$} & $\mathrm{B}-\mathrm{T}$ & 1152 & 1629 & 0.71 & $\mathrm{C}$ \\
\cline { 4 - 9 } 2 & Sudirman & & $\mathrm{T}-\mathrm{B}$ & 1392 & 1629 & 0.85 & $\mathrm{D}$ \\
\hline 3 & & $4 / 2 \mathrm{UD}$ & $\mathrm{S}-\mathrm{U}$ & 1722 & 1629 & 1.06 & $\mathrm{~F}$ \\
\hline
\end{tabular}




\begin{tabular}{|c|c|c|c|c|c|c|c|}
\hline & $\begin{array}{l}\text { Jl. Panglima } \\
\text { sudirman }\end{array}$ & & $U-S$ & 1236 & 1629 & 0.76 & D \\
\hline \multirow{2}{*}{4} & \multirow{2}{*}{ Jl. Kanjeng Jimat } & \multirow{2}{*}{$2 / 2 \mathrm{UD}$} & $\mathrm{T}-\mathrm{B}$ & 1142 & 1629 & 0.70 & $\mathrm{C}$ \\
\hline & & & $\mathrm{B}-\mathrm{T}$ & 1053 & 1629 & 0.65 & $\mathrm{C}$ \\
\hline \multirow{2}{*}{5} & \multirow{2}{*}{ Jl. Kanjeng Jimat } & \multirow{2}{*}{$2 / 2 \mathrm{UD}$} & $S-U$ & 1511 & 2182 & 0.69 & $\mathrm{C}$ \\
\hline & & & $\mathrm{U}-\mathrm{S}$ & 1264 & 2182 & 0.58 & $\mathrm{C}$ \\
\hline \multirow{2}{*}{6} & \multirow{2}{*}{ Jl. Khairil Anwar } & \multirow{2}{*}{$2 / 2 \mathrm{UD}$} & $\mathrm{B}-\mathrm{T}$ & 983 & 1692 & 0,58 & $\mathrm{C}$ \\
\hline & & & $\mathrm{T}-\mathrm{B}$ & 855 & 1692 & 0,51 & $\mathrm{C}$ \\
\hline \multirow{2}{*}{7} & \multirow{2}{*}{$\begin{array}{c}\text { Jl. Rng. } \\
\text { Ronggowarsito }\end{array}$} & \multirow{2}{*}{$2 / 2 \mathrm{UD}$} & $\mathrm{B}-\mathrm{T}$ & 869 & 1506 & 0,58 & $\mathrm{C}$ \\
\hline & & & $\mathrm{T}-\mathrm{B}$ & 767 & 1506 & 0,51 & $\mathrm{C}$ \\
\hline
\end{tabular}

\section{Sumber : Hasil Analisa}

Tabel 6. Prediksi Volume, Kapasitas, Derajat Kejenuhan dan Tingkat Pelayanan Pada

Ruas Jalan Sekitar Lokasi Studi Tanpa Pengembangan Tahun 2024 Puncak siang

\begin{tabular}{|c|c|c|c|c|c|c|c|}
\hline No & Ruas & Type & $\begin{array}{l}\text { Perger } \\
\text { akan }\end{array}$ & $\begin{array}{l}\text { Volume } \\
\text { (smp/jam) }\end{array}$ & $\begin{array}{l}\text { Kapasitas } \\
\text { (smp/jam) }\end{array}$ & DS & LOS \\
\hline \multicolumn{8}{|c|}{ Puncak Siang (11:00 s/d 14:00) } \\
\hline \multirow{2}{*}{1} & Jl. Brigjend & \multirow{2}{*}{$2 / 2 \mathrm{D}$} & $\mathrm{S}-\mathrm{U}$ & 1322 & 1692 & 0.78 & $\mathrm{D}$ \\
\hline & Sutran & & $U-S$ & 1424 & 1692 & 0.84 & $\mathrm{D}$ \\
\hline \multirow{2}{*}{2} & J1. Panglima & \multirow{2}{*}{$4 / 2 \mathrm{UD}$} & $\mathrm{B}-\mathrm{T}$ & 1072 & 1629 & 0.66 & $\mathrm{C}$ \\
\hline & Sudirman & & $\mathrm{T}-\mathrm{B}$ & 1224 & 1629 & 0.75 & $\mathrm{D}$ \\
\hline \multirow{2}{*}{3} & Jl. Panglima & \multirow{2}{*}{$4 / 2 \mathrm{UD}$} & $\mathrm{S}-\mathrm{U}$ & 1515 & 1629 & 0.93 & $\mathrm{E}$ \\
\hline & sudirman & & $\mathrm{U}-\mathrm{S}$ & 1466 & 1629 & 0.90 & $\mathrm{E}$ \\
\hline \multirow{2}{*}{4} & \multirow{2}{*}{ Jl. Kanjeng Jimat } & \multirow{2}{*}{$2 / 2 \mathrm{UD}$} & $\mathrm{T}-\mathrm{B}$ & 1049 & 1629 & 0.64 & $\mathrm{C}$ \\
\hline & & & $\mathrm{B}-\mathrm{T}$ & 1040 & 1629 & 0.64 & $\mathrm{C}$ \\
\hline \multirow{2}{*}{5} & \multirow{2}{*}{ Jl. Kanjeng Jimat } & \multirow{2}{*}{$2 / 2 \mathrm{UD}$} & $\mathrm{S}-\mathrm{U}$ & 1439 & 2182 & 0.66 & $\mathrm{C}$ \\
\hline & & & $\mathrm{U}-\mathrm{S}$ & 1242 & 2182 & 0.57 & $\mathrm{C}$ \\
\hline \multirow{2}{*}{6} & \multirow{2}{*}{ J1. Khairil Anwar } & \multirow{2}{*}{$2 / 2 \mathrm{UD}$} & $\mathrm{B}-\mathrm{T}$ & 634 & 1692 & 0,37 & B \\
\hline & & & $\mathrm{T}-\mathrm{B}$ & 763 & 1692 & 0,45 & $\mathrm{C}$ \\
\hline \multirow{2}{*}{7} & \multirow{2}{*}{$\begin{array}{c}\text { Jl. Rng. } \\
\text { Ronggowarsito }\end{array}$} & \multirow{2}{*}{$2 / 2 \mathrm{UD}$} & $\mathrm{B}-\mathrm{T}$ & 665 & 1506 & 0,44 & B \\
\hline & & & $\mathrm{T}-\mathrm{B}$ & 900 & 1506 & 0,60 & $\mathrm{C}$ \\
\hline
\end{tabular}

Sumber : Hasil Analisa

Tabel 7. Prediksi Volume, Kapasitas, Derajat Kejenuhan dan Tingkat Pelayanan Pada

Ruas Jalan Sekitar Lokasi Studi Tanpa Pengembangan Tahun 2024 Puncak sore 


\begin{tabular}{|c|c|c|c|c|c|c|c|}
\hline No & Ruas & Type & $\begin{array}{l}\text { Perger } \\
\text { akan }\end{array}$ & $\begin{array}{l}\text { Volume } \\
\text { (smp/jam) }\end{array}$ & $\begin{array}{l}\text { Kapasitas } \\
\text { (smp/jam) }\end{array}$ & DS & LOS \\
\hline \multicolumn{8}{|c|}{ Puncak Sore (16:00 s/d 19:00) } \\
\hline \multirow{2}{*}{1} & Jl. Brigjend & \multirow{2}{*}{$2 / 2 \mathrm{D}$} & $\mathrm{S}-\mathrm{U}$ & 1180 & 1692 & 0.70 & $\mathrm{C}$ \\
\hline & Sutran & & $U-S$ & 967 & 1692 & 0.57 & $\mathrm{C}$ \\
\hline \multirow{2}{*}{2} & Jl. Panglima & \multirow{2}{*}{ 4/2 UD } & $\mathrm{B}-\mathrm{T}$ & 920 & 1629 & 0.56 & $\mathrm{C}$ \\
\hline & Sudirman & & $\mathrm{T}-\mathrm{B}$ & 1065 & 1629 & 0.65 & $\mathrm{C}$ \\
\hline \multirow{2}{*}{3} & Jl. Panglima & \multirow{2}{*}{ 4/2 UD } & $\mathrm{S}-\mathrm{U}$ & 1414 & 1629 & 0.87 & $\mathrm{E}$ \\
\hline & sudirman & & $\mathrm{U}-\mathrm{S}$ & 1056 & 1629 & 0.65 & $\mathrm{C}$ \\
\hline \multirow{2}{*}{4} & \multirow{2}{*}{ Jl. Kanjeng Jimat } & \multirow{2}{*}{ 2/2 UD } & $\mathrm{T}-\mathrm{B}$ & 1161 & 1629 & 0.71 & $\mathrm{C}$ \\
\hline & & & $\mathrm{B}-\mathrm{T}$ & 953 & 1629 & 0.59 & $\mathrm{C}$ \\
\hline \multirow{2}{*}{5} & \multirow{2}{*}{ Jl. Kanjeng Jimat } & \multirow{2}{*}{$2 / 2 \mathrm{UD}$} & $\mathrm{S}-\mathrm{U}$ & 1289 & 2182 & 0.59 & $\mathrm{C}$ \\
\hline & & & $\mathrm{U}-\mathrm{S}$ & 1253 & 2182 & 0.57 & $\mathrm{C}$ \\
\hline \multirow{2}{*}{6} & \multirow{2}{*}{ J1. Khairil Anwar } & \multirow{2}{*}{$2 / 2 \mathrm{UD}$} & $\mathrm{B}-\mathrm{T}$ & 546 & 1692 & 0,32 & B \\
\hline & & & $\mathrm{T}-\mathrm{B}$ & 645 & 1692 & 0,38 & B \\
\hline \multirow{2}{*}{7} & \multirow{2}{*}{$\begin{array}{c}\text { Jl. Rng. } \\
\text { Ronggowarsito }\end{array}$} & \multirow{2}{*}{$2 / 2 \mathrm{UD}$} & $\mathrm{B}-\mathrm{T}$ & 714 & 1506 & 0,47 & $\mathrm{C}$ \\
\hline & & & $\mathrm{T}-\mathrm{B}$ & 872 & 1506 & 0,58 & $\mathrm{C}$ \\
\hline
\end{tabular}

\section{Sumber : Hasil Analisa}

Tabel 8. Prediksi Volume, Kapasitas, Derajat Kejenuhan dan Panjang Antrian Pada Persimpangan Tanpa Pengembangan Tahun 2024

\begin{tabular}{|c|c|c|c|c|c|c|c|c|}
\hline Persim-pangan & $\begin{array}{l}\text { Periode } \\
\text { Puncak }\end{array}$ & Pendekat & $\begin{array}{c}\text { Kode } \\
\text { Pendekat }\end{array}$ & $\begin{array}{c}\text { Volume } \\
\text { (smp/ } \\
\text { jam) }\end{array}$ & $\begin{array}{l}\text { Kapasitas } \\
\text { (smp/jam) }\end{array}$ & DS & $\begin{array}{l}\text { Panjang } \\
\text { Antrian } \\
\text { (meter) }\end{array}$ & LOS \\
\hline \multirow{9}{*}{$\begin{array}{c}\text { Jl. Panglima } \\
\text { Sudirman - Jl. } \\
\text { Brigjen Sutran } \\
\text { - Jl. Panglima } \\
\text { Sudirman }\end{array}$} & \multirow{3}{*}{$\begin{array}{l}\text { Puncak } \\
\text { Pagi }\end{array}$} & Selatan & PS & 1722 & 1629 & 1.06 & 35 & \multirow{3}{*}{$\mathrm{E}$} \\
\hline & & Timur & BJ & 1142 & 1629 & 0.70 & 29 & \\
\hline & & Utara & PS & 1392 & 1629 & 0.85 & 28 & \\
\hline & \multirow{3}{*}{$\begin{array}{l}\text { Puncak } \\
\text { Siang }\end{array}$} & Selatan & PS & 1515 & 1629 & 0.93 & 35 & \multirow{3}{*}{$\mathrm{D}$} \\
\hline & & Timur & BJ & 1040 & 1629 & 0.64 & 25 & \\
\hline & & Utara & PS & 1224 & 1629 & 0.75 & 28 & \\
\hline & \multirow{3}{*}{$\begin{array}{l}\text { Puncak } \\
\text { Sore }\end{array}$} & Selatan & PS & 1056 & 1629 & 0,65 & 32 & \multirow{3}{*}{$\mathrm{C}$} \\
\hline & & Timur & $\mathrm{BJ}$ & 953 & 1629 & 0,59 & 28 & \\
\hline & & Utara & PS & 1065 & 1629 & 0,65 & 21 & \\
\hline & \multirow{3}{*}{$\begin{array}{l}\text { Puncak } \\
\text { Pagi }\end{array}$} & Utara & $\mathrm{BJ}$ & 1420 & 1506 & 0,94 & 28 & \multirow{3}{*}{$\mathrm{D}$} \\
\hline & & Timur & $\mathrm{KJ}$ & 1186 & 1692 & 0,70 & 28 & \\
\hline & & Barat & $\mathrm{KJ}$ & 1268 & 1692 & 0,75 & 24 & \\
\hline & & Utara & $\mathrm{BJ}$ & 1481 & 1506 & 0,98 & 31 & $\mathrm{D}$ \\
\hline
\end{tabular}




\begin{tabular}{|c|c|c|c|c|c|c|c|c|}
\hline Kanjeng & Puncak & Timur & $\mathrm{KJ}$ & 777 & 1692 & 0,45 & 28 & \\
\hline - $\quad \mathrm{Jl}$ & Siang & Barat & $\mathrm{KJ}$ & 1368 & 1692 & 0,81 & 35 & \\
\hline \multirow{3}{*}{$\begin{array}{l}\text { BrigjendSoetran } \\
-\quad \text { Jl. Kanjeng } \\
\text { Jimat }\end{array}$} & \multirow{3}{*}{$\begin{array}{l}\text { Puncak } \\
\text { Sore }\end{array}$} & Utara & BJ & 1537 & 1506 & 1.02 & 28 & \multirow{3}{*}{ C } \\
\hline & & Timur & $\mathrm{KJ}$ & 1126 & 1692 & 0,67 & 35 & \\
\hline & & Barat & $\mathrm{KJ}$ & 861 & 1692 & 0,51 & 32 & \\
\hline
\end{tabular}

Sumber : Hasil Analisa

Dari beberapa hasil analisa diatas dapat disimpulkan bahwa ruas jalan dan persimpangan yang ada di sekitar wilayah Gedung Olah Raga kinerjanya masih bagus, nilai DS (Derajat Kejenuhan) yang kebanyakan masih tahap normal. Artinya Nilai Derajat kejenuhan pada ruas jalan dan persimpangan jalan sekitar masih memenuhi persyaratan MKJI (DS $<0,75)$ pada prediksi Tahun 2024 tanpa pengembangan.

\section{KESIMPULAN}

Berdasarkan perhitungan dari microsoft Excel,dapat diketahui bahwa :

1. Dari data tabel pada bab IV dapat disimpulkan pada tahun 2019 atau data existing, kinerja ruas jalan Brigjend Sutran di depan Gedung Olah Raga, Lalu-Lintas Harian Rata-Rata (LHR) pada jam sibuk pagi, jam sibuk siang, jam sibuk sore masih bagus dengan besar 1.680 smp/jam (LV), 559 smp/jam (HV), 13.326 smp/jam (MC).

2. Dari data tabel pada bab IV dapat disimpulkan pada tahun 2019 atau data existing, kinerja ruas jalan dan persimpangan sekitar Pembangunan Gedung Olah Raga derajat kejenuhan (DS) rata-rata masih bagus dengan nilai 0,50 yang berarti tingkat pelayanan (LOS) rata-rata $\mathrm{C}$.

3. Dari data tabel pada bab IV dapat disimpulkan bahwa V/C rasio (DS) dan tingkat pelayanan (LOS) pada ruas jalan dan persimpangan sekitar wilayah studi dengan pengembangan kawasan tahun 2024 masih cukup bagus, ini dapat dilihat dari besaran derajat kejenuhan (DS) yang masih dalam tahap normal yaitu 0,70 dan tingkat pelayanan (LOS) C.

\section{SARAN}

Saran-saran untuk untuk penelitian lebih lanjut untuk menutup kekurangan penelitian. Tidak memuat saran-saran diluar untuk penelitian lanjut.

\section{UCAPAN TERIMAKASIH}

Dalam penyusunan artikel ini, penulis ucapkan terimakasih kepada dosen pembimbing dan Universitas Kadiri. Penulis berharap agar artikel ini dapat bermanfaat bagi pembaca. 


\section{DAFTAR PUSTAKA}

[1] S. Sukirman, Perkerasan lentur jalan raya, vol. 2. 1999.

[2] M. Atho 'ur Rohman, D. Kartikasari, K. Kunci, and : Kemacetan, "ANALISA KEMACETAN LALU LINTAS PADA PASAR TRADISIONAL DI RUAS JALAN SEKARAN-MADURAN," J. CIVILA, vol. 1, no. 2, pp. 1-6, 2016.

[3] A. D. Limantara, A. I. Candra, and S. W. Mudjanarko, "Manajemen Data Lalu Lintas Kendaraan Berbasis Sistem Internet Cerdas Ujicoba Implementasi Di Laboratorium Universitas Kadiri,” 2017.

[4] S. Awiyaningsih, H. Moetriono, and D. T. Sipil, "ANALISIS DAMPAK LALU LINTAS AKIBAT PEMBANGUNAN MALL LAGOON AVENUE SUNGKONO TERHADAP KINERJA SIMPANG DI JL MAYJEND SUNGKONO - HR MUHAMMAD SURABAYA,” Tek. Eng. Sains J., vol. 2, no. 2, pp. 131-134, 2018.

[5] A. Y. Nurkafi, S. Winarto, and A. I. Candra, "ANALISA KINERJA SIMPANG TAK BERSINYAL JALAN SIMPANG BRANGGAHAN NGADILUWIH KABUPATEN KEDIRI,”Jurmateks, vol. 2, no. 1, pp. 164-178, 2019.

[6] D. A. Limantara, Y. Cahyo, and S. W. Mudjanarko, "Pemodelan Sistem Pelacakan LOT Parkir Kosong Berbasis Sensor Ultrasonic Dan Internet Of Things ( IOT ) Pada Lahan Parkir Diluar Jalan,” Semin. Nas. Sains dan Teknol., vol. 1, no. 2, pp. 1-10, 2017.

[7] E. H. Sunyoto, A. Ridwan, and S. Winarto, "MANAJEMEN REKAYASA LALU LINTAS PENGEMBANGAN WISATA KAMPUNG COKLAT,”Jurmateks, vol. 2, no. 1, pp. 29-38, 2019.

[8] B. A. Harsono, S. Winarto, and Y. C. S, "PERENCANAAN PENINGKATAN JALAN PADA RUAS JALAN PACITAN-NGADIROJO,”Jurmateks, vol. 1, no. 2, pp. 291-302, 2018.

[9] R. Rahman, “Analisa Dampak Lalu Lintas (Studi Kasus: Studi Kemacetan di Jalan Ngagel Madya Surabaya)," SMARTek, vol. 8, no. 4, pp. 317-332, 2010.

[10] A. Kurniawan, S. Winarto, and Y. Cahyo, "Studi Perencanaan Peningkatan Jalan Pada Ruas Jalan Jalur Lintas Selatan Giriwoyo - DUWET STA. 10+000 - STA. 15+000,” jurmateks, vol. 2, no. 1, pp. 37-47, 2019.

[11] A. I. Candra, "STUDI KASUS STABILITAS STRUKTUR TANAH LEMPUNG PADA JALAN TOTOK KEROT KEDIRI MENGGUNAKAN LIMBAH KERTAS,” UKaRsT, 2018, doi: 10.30737/ukarst.v2i2.255.

[12] S. Dikun and D. Arief, "Strategi Pemecah Masalah Luas Bangunan dan Lalu Lintas," Bahan Semin. Dampak Pemanfaat. Intensitas Lahan Gedung Tinggi/Superblok di Jakarta terhadap lalu lintasdisekitarnya, 1993. 
[13] D. P. Umum, "Buku III Spesifikasi Umum Bidang Jalan dan Jembatan.” Jakarta, 2007.

[14] S. J. Legowo and D. Anggoro, "Studi Evaluasi Dampak Lalu Lintas Akibat Pembangunan Stasiun Pengisian Bahan Bakar Umum ( Spbu ) Manahan," pp. 601-609, 2014.

[15] E. Gardjito, "STUDY PERENCANAAN GEOMETRIK, PERKERASAN JALAN DAN PERENCANAAN ANGGARAN BIAYA PADA JALAN RAYA KALIDAWIR-Ds. NGUBALAN Kec. KALIDAWIR," UKaRsT, vol. 1, no. 2, p. 11, 2017.

[16] F. A. Lestari and Y. Apriyani, "ANALISIS DAMPAK LALU LINTAS AKIBAT ADANYA PUSAT PERBELANJAAN DIKAWASAN PASAR PAGI PANGKALPINANG TERHADAP KINERJA RUAS JALAN," J. Fropil, vol. 2, no. 1, pp. 32-44, 2014.

[17] H. Kustarto, H. Wibisana, P. Studi, T. Sipil, and M. Sungkono, "Analisa karakteristik lalu lintas di ruas jalan mayjen sungkono kotamadya surabaya," vol. 3, no. 1, 2013.

[18] A. Kurniawan, S. Winarto, and Y. C. S. P, "STUDI PERENCANAAN PENINGKATAN JALAN PADA RUAS JALAN JALUR LINTAS SELATAN GIRIWOYO - DUWET STA. 10+000 - STA. 15+000,” Jurmateks, vol. 2, no. 1, pp. 39-50, 2019.

[19] [Kementerian PUPR]. Kementerian Pekerjaan Umum dan Perumahan Rakyat direktorat jendral bina marga and D. J. B. Marga, "Manual Desain Perkerasan Jalan," Nomor 02/M/BM/2013, 2013.

[20] O. Z. Tamin, Perencanaan Dan Pemodelan Transportasi. Bandung: ITB, 2003. 